\title{
Tragic Aftermath of Californian Jungle Fire and Hawaiian Volcano Outburst, a Warning about Persistently Rising Global Warming, Resulting into High Rated Disaster's Chain
}

\author{
Malik Muhammad Nazeer \\ H\#70, Street 35-A, I-9/4, Islamabad, Pakistan \\ Email: naz188nbsg@gmail.com
}

How to cite this paper: Nazeer, M.M. (2019) Tragic Aftermath of Californian Jungle Fire and Hawaiian Volcano Outburst, a Warning about Persistently Rising Global Warming, Resulting into High Rated Disaster's Chain. Open Access Library Journal, 6: e5118.

https://doi.org/10.4236/oalib.1105118

Received: December 13, 2018

Accepted: January 27, 2019

Published: January 30, 2019

Copyright $\odot 2019$ by author(s) and Open Access Library Inc.

This work is licensed under the Creative Commons Attribution International License (CC BY 4.0).

http://creativecommons.org/licenses/by/4.0/

\begin{abstract}
Earthglobe is almost at flash point with respect to global heat contents and temperature and any sizeable further addition of heat to its environment will result into huge disaster of life, property and infrastructure at multiple locations on the globe. The recent example of this is the aftermath of Californian forest fires (2017-2018) and Hawaii volcano eruption as elaborated in this treatise. This has resulted into 7 main catastrophic events over the Earth globe in its first round, while in $2^{\text {nd }}$ round, all the previous same 7 or similar event in the same or an area close to it are repeated with one more event added in the list. These wildfires add large quantity of heat directly to the globe and even more through abstraction of out going global heat radiation by their generated green house gasses, pollution and soot. The $2^{\text {nd }}$ round is perhaps also supported by Hawaii volcanic eruption. The $3^{\text {rd }}$ round has mainly completed and few expected events are yet in pipe line, but California jungle fire of November 2018 has strengthened its attacks again. The mechanics and tracks of its attacks with pulled in of its allies has been elaborated in this work with role of this wildfire and its all children; heat, soot, pollution and green house gasses in possible boast of global heat contents and temperature. It is observed that disastrous aftermath from all such heating events in the north are contained mainly in Northern Hemisphere, while contrary to this; some of such events in the south have hard strikes on the North. It is requested that Global heat contents rise, jungle fire and volcanic eruptions must be completely stopped by all means because this causes widespread disaster mainly over the tropical regions of Globe as experienced from Californian Jungle Fire.
\end{abstract}




\section{Subject Areas}

\section{Atmospheric Sciences}

\section{Keywords}

Remote Prey of California Wildfire, Aftermath, Triggered, Generated

Calamities, Hot Spots, Westerly-Easterly Diode, More and Rapid

Temperature Fluctuations, Pineapple Atmospheric River Express

\section{Introduction}

The earth globe is almost at the triggering or flash point as far as Global Heat Contents and Temperature are concerned particularly with extraordinary booming boast after 1960 (Figures 1-3). The tragedy is that no measure to defuse it by its most efficient outflow through extension of water evaporation and precipitation cycle as suggested in reference [1] has ever been considered. Thus, these are rising at very fast rate, particularly after 1960 as can be observed in graphs presented in Figure 1 [2]. Figure 2 [3] shows the major wildfire events in North America (blue curve) and their burned bushes area (red curve), which is proportional to their immediate heat input to the Globe. The green curve (Figure 2) shows the jungle area burned by major wildfire of the other World

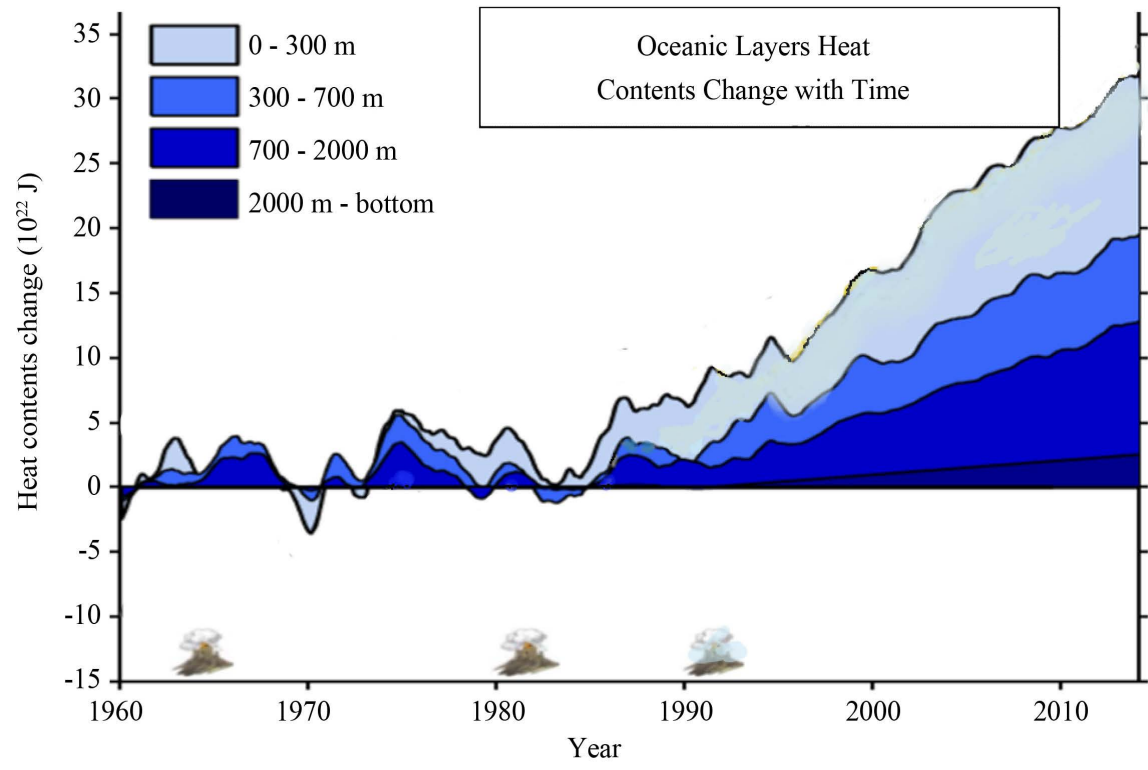

Figure 1. The graphs above show the Estimate of the ocean energy budget relative to 1958-1962 base period, and is claimed to be more realistic. The three major volcanic eruptions are also shown and their ultimate cooling effect may clearly be observed. The oceanic total heat is $93 \%$ the total Global heat contents and only $7 \%$ is the total heat energy of land + ice + atmosphere. From 1971 onward: The annual rate of total Oceanic heat $=10 \times(31.8+19.1+12.7+2.3) /(2014-1971)=15.33 \times 10^{21} \mathrm{~J}=15.33 \mathrm{ZJ}$. The annual rate of total global heat contents $=10 \times(31.8+19.1+12.7+2.3+4.96) /(2014-$ 1971) $=16.48 \mathrm{ZJ}$. 


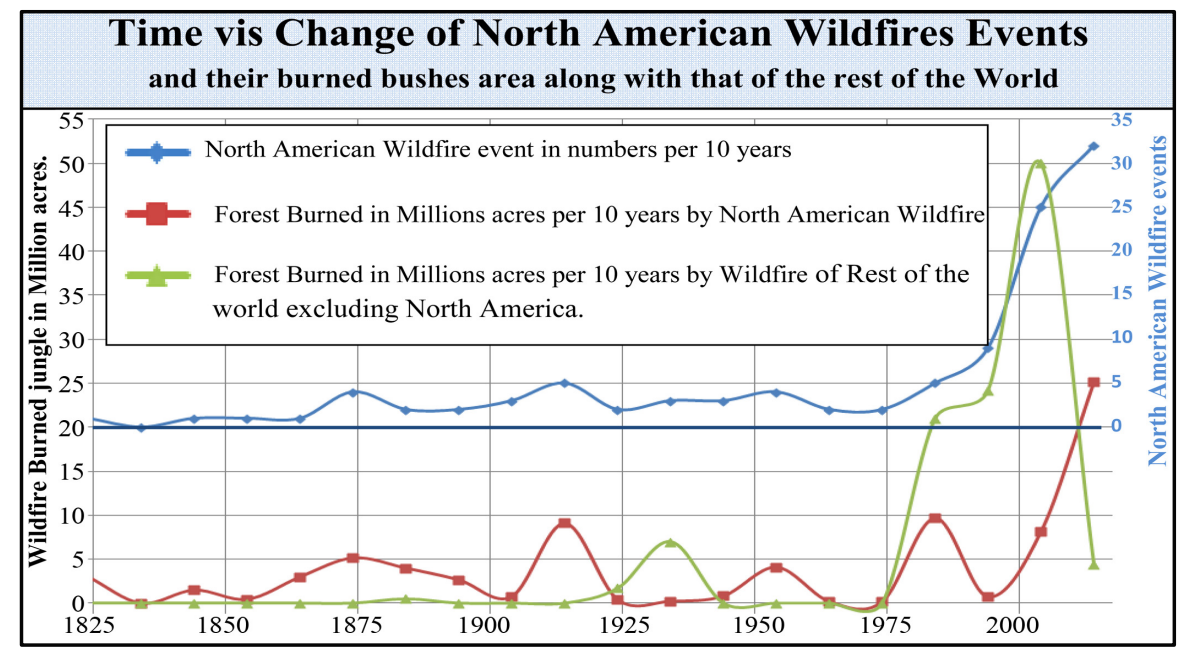

Figure 2. North American major Wild Fire Hazards and their burned forest area in millions acres, a quantity proportional to the heat input to the Globe along with burned areas by Wildfire in rest of the world in million acres of the jungle (Wikipedia, list of wildfires events). 1973 seems to be a turning point in Global fire events as well as their heat input.

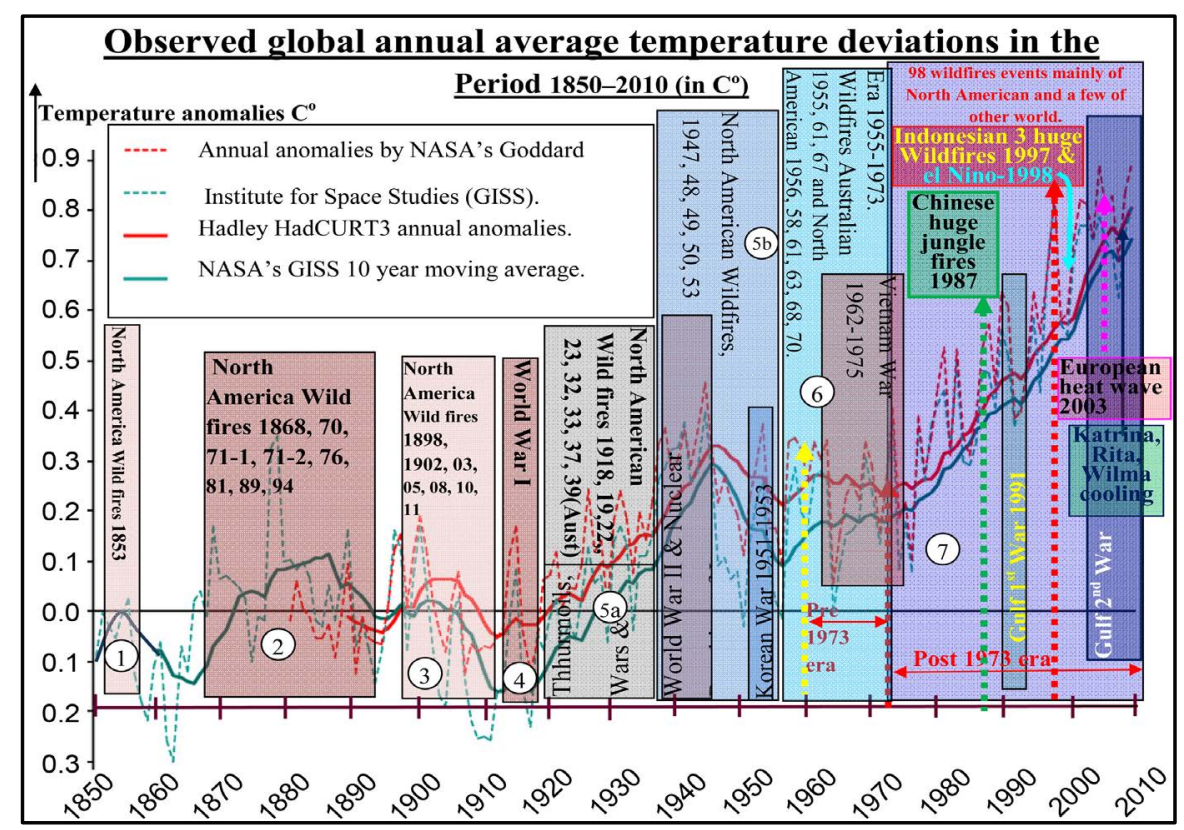

Figure 3. Rise, fall and rates in Temperature graphs matches with the start, end and quantities of heat inputs by the large events marked above. Cooling after the event catered by water evaporation and precipitation cycle with heat export and cold fresh water and ice import is forced by local high temperature in eras marked $1-6$ for the group of events shown above. The continuous steep rise of temperature after 1960 (era 7 and 8 ) is attributed to some particularly extraordinary event overruling and dominating cooling routine at the end of all other events.

excluding North America. These curves show clearly their mutual coherence and mutual bilateral support with that of Figure 1 and Figure 3 in their mutual growth rates, particularly at highly dangerous speed after 1973. The high global temperature is triggering fire at jungles by furnishing suitable high temperature, 
providing dried wood fuels and oxygen in abundance through high speed wind for its widespread disaster. The heat, soot, pollution and green house gasses produced by this is adding much more to the Global heat contents and temperature in turn through obstructing the global heat outflow to the outer universe. At such scenario, any sizeable further addition of heat to the environment triggered by this Global heat and temperature flasher or by any other means at any critical location will result into huge disaster of life, property and infrastructure not only at the flashing location, but also at number of other locations on the Globe. As a result of these sudden input of large amount of heat directly to the globe at particular location in a limited area and time on one hand and global heat outflow abstraction by its developed soot, pollutions and green house gasses many times more than its direct input on the other hand causes wide spread disaster over all the Globe. The aftermath of Californian jungle fire and Hawaii volcano outburst as discussed below is an example of this tragic outcome of Global heating. The most critical in this respect are the land areas around the tropical zones, especially in Northern Hemisphere, where strong easterly winds or some westerly are ready to drag this heat to ocean. Here a large part of this heat is absorbed by the Ocean, a part retained as latent heat of evaporated water absorbed by wind from the ocean surface, while a part is retained to heighten the kinetic energy of the wind. The first part increases the global heat contents and temperature, the $2^{\text {nd }}$ part goes away to upper atmosphere and thus defused mostly with disastrous rains and floods, while the $3^{\text {rd }}$ part results in disaster through huge storms, hurricanes, tornados, cyclones and typhoons. The first part after a while follows the same $1^{\text {st }}, 2^{\text {nd }}$ and $3^{\text {rd }}$ parts with the help of easterlies and westerly till its energy comes somewhat at globally balanced and stable state. These phenomena may be observed from the Global temperature graph (Figure 3) [4] with first 3 bulges having coherence to heat input by North American wildfires; the first during 1853 , the $2^{\text {nd }} 1868-1894$ and $3^{\text {rd }} 1898-1911$ [3] followed by cooling through water evaporation and precipitation cycle enforced by local extraordinary high temperature resulting into heavy rain and snow storms. The $4^{\text {th }}$ small bulge pertain to World Wars I and 5th (both a and b) large and prolonged bulge pertains to North American wildfires during 1918-1954, World war II, nuclear bombing of Japan and wars and turmoil prior to World war II and small clink/bulge pertaining to Korean War. The era shown by No. 6 and 7 indicate extraordinary temperature and Global heat contents rise (also seen in Figure 1 and Figure 2) with minute bulges or clinks, showing effect of Vietnam and Gulf wars. On annual scale Chinas-1987 and 1ndonician-1997 Wildfires events, European heat wave of 2003 and its generated Wildfires events and thereby developed and brought up tens of hurricane every year, particularly Katrina, Rita and Wilma defusing global heat and lowering temperature a bit are evident in the graphs (Figure 3). All these have quite minute time bound effect or response and could not force any major hump or slump in the Global temperature curve as experienced in previous 5 eras. Thus it diagnosis that actual and monster culprit behind this huge continuous rise of temperature is something 
else. These however, also indicate, rather confirm and pronounce the bilaterally active correlation among Global warming, wildfires, heat waves and other hazards. The heat and pollution from the extensive use of explosive in Gulf war of 2003-2010 propagated heat waves of 2003 in Europe and wildfires of 2003-2010 in all the world which helped already high global temperature to enforce series of hurricanes a few like Isabel of 2003, Charley, Frances, Ivan and Jeanne of 2004, Dennis, Katrina, Rita, Wilma, Emily of 2005 (out of 31 such events only in 2005) to offload the some of the Global heat contents.

The Monster activist behind extraordinary status of era shown by 6 and 7 (Figure 3) needs too extensive explanation and will be shortly presented in different treatise. Global warming facilitates wildfire flourishing which generate Heat and pollution etc. and these onward generate hurricanes, typhoons, tornadoes, snow and wind storms to devastate at some other places along with boast in Global heat and temperature. The recent example of this is Forest Fires (2017-2018) in the California state of USA. This has resulted into 7 main catastrophic events (Figure 4) over the Earth globe in first round, while the same 7 are repeated in sequence and one more excluding various other have met within its $2^{\text {nd }}$ round possibly supported by other wildfires in Europe and volcanic eruptions of Hawaii and others. The $3^{\text {rd }}$ round also has almost completed lashing on Philippine, China, USA and Europe etc for the third time with the help of California jungle fire of November 2018. The $3^{\text {rd }}$ round was a bit week under winter cover of Northern hemisphere and it seems that $4^{\text {th }}$ will be of higher intensity as compared to $3^{\text {rd }}$ with the help of summer of 2019. Most probably, the targets will be the same with a little bit deflection, but more disaster. Fortunately the curse of this tragedy is divided and distributed over the seven or eight blocks on the Globe in place of all and whole the curse at one place and that too distributed in two, three or four rounds. At some places it has struck as the heat waves, at others as hurricane and storm family, at some places as snow storms and at other places both heat waves and storms one after the other. The situation is extremely

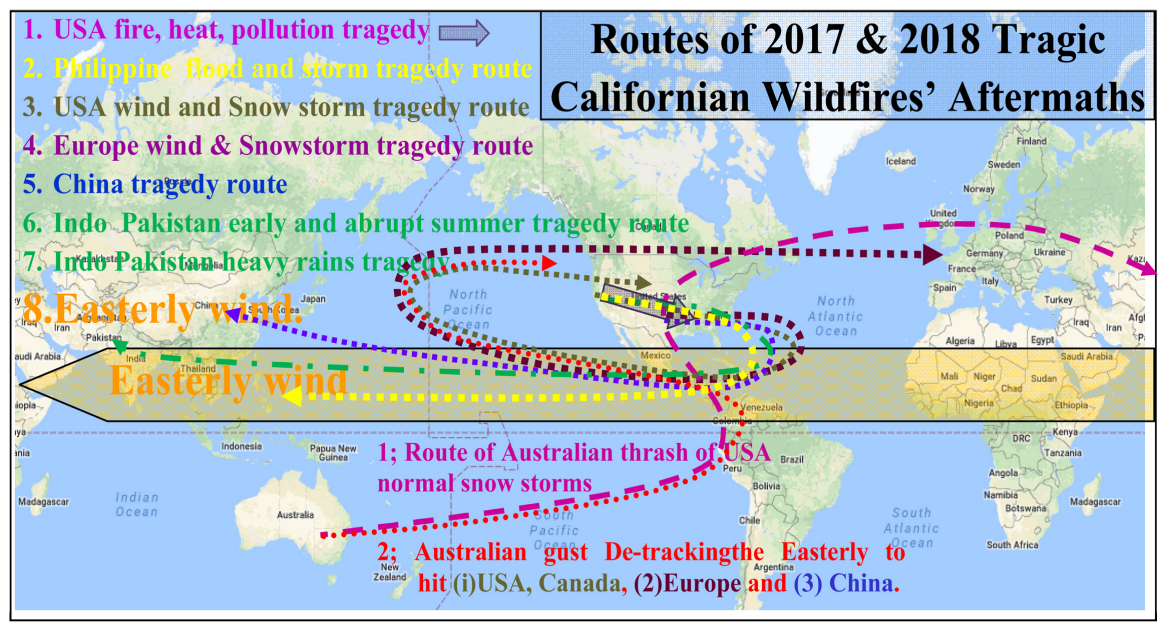

Figure 4. Tracks of first round of California wildfire sponsored/fired storms or heat waves. Overlapping is avoided. 
alarming, as in the present state of Global warming, all such hazard will surely generate wide spread extreme level calamities. All such hot spots of possible Wildfires must be marked and the preventive as well as overpowering measures must be made and monitored at International level.

\section{Californian Jungle Fire}

The curse of California jungle fire, both of 2017 and 2018 combined has already fallen on various parts of the world in almost two rounds by August, 2018. The $3^{\text {rd }}$ round was expected to complete before the end of 2018, diminished by the winter of ending 2018, but Californian Jungle Fire of November, 2018 has reduced this hope and $4^{\text {th }}$ round may complete before the mid of 2019 if its prominence is not buried under other burning issues. The first two round, their disaster and route mechanics are given below.

\subsection{First Round of Disasters and Their Routes Mechanics}

Followings are the prey to the first round of this tragedy almost before June 2018.

1) The first prey of this tragedy is the California itself and various other states of USA on its east and southeast with blast of heat, temperature and pollution over and above their routine values. Then, hovering and rolling over the north western Atlantic this train of heat gusts is continuously dragged on by the trains of easterly/trade wind over the huge heat capacitors North Western Atlantic Ocean, Caribbean Sea and Mexican Gulf (Figure 4) to heat them up to prolong its disastrous role through fast heat absorption by sea under high air-water temperature difference and its slow back transfer to the air under then comparatively low water-air temperature difference and through water evaporation. It then rode on the easterly wind train to heat the Pacific Ocean on its way. This heating of the oceans by the high temperature trains of gust is like laying the eggs/seeds on the route which grow as the season become favorable to it.

2) Then Philippine fell into its $2^{\text {nd }}$ prey through huge storm, rainfall and tidal floods as the Californian heated gusts riding on the Easterly wind train (Figure 4) and dragging the water vapors from Atlantic Ocean, Caribbean and Mexican Sea and finally from the PacificOcean approached the Philippine without any other de-tracking major activist. It was ruined badly with wind storm followed by a heavy flood. The route of this catastrophe is shown in the world map Figure 4.

3) Then the easterly/trade wind train carrying Californian wildfire heat was pushed towards the North by the thrust of Australian desert heated wind which usually causes early winter snow storms in the southern states of USA from the Caribbean and Mexican sea side. As shown in the map (Figure 4), the tracks of two winds combined were thus rerouted and these traversed a large semi circle, rather a U-turn over the pacific, absorbed the huge quantity of water vapors and attacked most of the USA states with extraordinary snow and wind storms ap- 
proaching USA from the northwest side. This was the $3^{\text {rd }}$ prey to this tragedy in which Emergency was to be declared by the USA Government. The above stated semi circular/U-turn route (with observer on the earth) because of variation in the linear speed of earth surface (the instant reference) along longitude due to earth rotation about its axis [5]. Thus north-west going air storms' western component become zero with respect to reference earth surface at some northern latitude and then it reverses itself and as it moves toward north, this eastward component carries on growing in speed, thus tracing a semicircle or $\mathrm{U}$ shaped track depending on the northern component of storm speed as compared to western component.

4) As shown in the map, the outer part of the above stated wind storms found its way over the Canada and Northern Atlantic and it has hit various countries of Europe with extremely sever snow and wind storm as its $4^{\text {th }}$ prey (Figure 4 ).

5) As the Australian desert heated wind changed its route towards south as a result of the shift of direct Sun rays towards south, this Californian based heated wind riding the Easterly wind train over the Atlantic and Carrabin Sea, regained its westward track on the Pacific Ocean with a bit shift towards north (Figure 4) by a small residual thrust of Australian gust and it attacked the China with severe storm and heavy rain. This was its $5^{\text {th }}$ prey in sequence.

6) As the Australian gust on the above stated track seized completely, this wind corrected its track and attacked the Indian Subcontinent forcing an early and extremely hard spring and summer on the southern side and more rains on northern side. Thus India and Pakistan along with similar curse on Far East Countries was its $6^{\text {th }}$ prey. This has damaged the wheat crop growth particularly on the southern side of Pakistan through imposition of too early, too sever and too long summer, also resulting into too many casualties by the Sun Stroke.

7) The $7^{\text {th }}$ prey was again Indian Subcontinent and it ended with extraordinary Monsoon rains in some parts of India and Pakistan along with that in the Fareast Countries.

\subsection{Second Round of Disasters with Their Routes Mechanics}

The second round of curse of California Jungle Fire was assisted by Hawaii and other volcanic eruption and some Wildfires in Europe fell on the world till almost October 2018.

1) The first prey of this tragedy in the $2^{\text {nd }}$ round was again the USA and Canada through an extraordinary heat wave.

2) Then Philippine fell again into its $2^{\text {nd }}$ prey again through huge storm, rainfall and tidal floods. Philippine was ruined badly again with wind storm followed by heavy flood. The route of this catastrophe is almost same as shown for the first round.

3) The $3^{\text {rd }}$ prey to this tragedy is USA and Carrabin Countries through some 9 10 intensified Atlantic storm/hurricane including Category 4 Florence hurricane [6]. This is not solely due to California Wildfire, but it has prominent role 
through the Atlantic Ocean heated during the first round.

4) The various countries of Europe are $4^{\text {th }}$ prey of this with heat waves, jungle fires and extremely severe storm and heavy rains enforced again by the Atlantic Ocean heated during the first round.

5) Japan was its $5^{\text {th }}$ prey in sequence with extreme heat wave and Jebi typhoon extremely severe than any typhoon in last 25 years [7] accompanied by heavy rains in early September 2018.

6) The $6^{\text {th }}$ prey was again China with severe storm and heavy rain.

7) The $7^{\text {th }}$ and $8^{\text {th }}$ prey was again India and Pakistan through waves of heavy rains and escalated temperature along with similar curse on the Fareast Countries. This has again damaged the growth of various crops and resulted into many casualties by the Sun Strokes.

Many other events all over the world may have happened as a result of California Jungle fire and Hawaii volcanic eruption at the scenario of extremely high Global Warming constantly rising at extremely high rate, but may not get widespread coverage in the media or could not come into notice of the author.

\subsection{Third Round}

The $3^{\text {rd }}$ round started by the October 2018, hitting Europe, Philippine, China, USA and India and Pakistan for the third time with storms, heavy rains and heat waves. In this round USA and Caribbean counties have suffered various escalated storms and hurricanes including Category 4 Hurricane Michael, the third-most intense Atlantic hurricane in the recent history to make landfall in the United States in terms of pressure, after 1935 Labor Day Hurricane and Hurricane Camille of 1969 [8]. USA have received heavy snow storm along with its second sever throw on some countries of Europe. The extraordinary heat and environmental temperature have affected the crops in Pakistan and accelerated the melting, slipping and lakes formations of glaciers, a huge risk of disasters by possible avalanches and floods. This may become very critical in $4^{\text {th }}$ round with the help of summer in Northern Hemisphere. The role of $3^{\text {rd }}$ round of this troika, the Global Heat Content and Temperature, a large Tribe of California Jungle fires and Hawaii volcanic eruption aftermath on world is not much sever being in winter.

\subsection{Fourth Round}

The $4^{\text {th }}$ round may be a some what harder than the $3^{\text {rd }}$ with the help of warmer season in the Northern Hemisphere. The huge Global heat contents and high global temperature may pull in some other Wildfires and volcanic eruption to intensify the disastrous role of this Gang. Thus the countries in the list of these rounds are warned to be vigilant and prepared to face the more sever Californian ruthlessness in $4^{\text {th }}$ round.

\section{Hawaii Volcano Outburst and Its Victims}

USA, Europe, Fareast Asia, Japan and China are early preys of the Hawaii vol- 
cano eruption with collaboration of California Wildfire as stated above and thus further tragic prey to this tragedy may be on its both east and west sides and thus North America, Europe, Eastern Asia and Indian Subcontinent are at the top of hit list of this Gang of Global Warming, Californian and other wildfires and Hawaiian and other volcanic eruptions over and above their sever escalation of the Global Temperature.

\section{Discussions}

The California Wildfire tragic attacks were supported by extremely high Global temperature and prolonged easterlies/trade winds, heated air Blast of Australian desert under high Sun activity and summer in the Northern Hemisphere in its first round. This round was prolonged, as well as weakened in its devastating intensity by the huge heat capacitance of its long track on Atlantic, Caribbean, Mexican Seas and Pacific Ocean with slow back release of heat captured during its first round. It has mainly lead to snow storm in North America and Europe; heavy rains, floods and storms in China and Philippine; heat waves in USA, Canada, Europe, India and Pakistan along with promoting global temperature rise and hence worldwide eruptions of tragic Problems. Similar calamities have resulted during its second round and bit harder are expected in its $4^{\text {th }}$. It is observed that Extreme Global warming is behind most of the global calamities. In every month, almost 12/13 disasters are reported in the tags/natural-disasters in the current events of 2018 [9], and majority of these are fed or fired by this Gang of Extreme Global Warming and its triggered and fueled Wildfires, volcanic eruptions and magma based earthquakes.

An interesting observation has come in view during this exercise, that almost all the calamites resulting from the California Wildfires and Hawaii volcanic eruption has fallen on only the Northern Hemisphere. So is the case of such other Wildfires, volcanic eruptions and heat based events in Europe, Northern Africa and Asia, particularly the Indian Subcontinent, while no immediate prominent affect of these is observed in Southern Hemisphere. However, such events in Southern Hemisphere have routine behavior contrary to this as shown in Figure 5. The Australian Wildfire and its desert's high radiations as per routine results in heavy snow storm in USA and helps USA bound Pineapple Express, Atmospheric River or Weather Storms (Figure 6 \& Figure 7) [10] [11], along with forwarding and forcing wind storm and hurricanes towards Far Eastern Asia, Japan and countries around Arabian Sea [5] over and above elevating the Monsoons in China, India and Pakistan; wind from West coast of Central and Southern Africa pushes and redirects Atlantic hurricanes and storms towards USA and Europe both in season and offseason; Southern American Wildfire lashes storm on Far Eastern Asia and Japan [5]. All these Northern Hemisphere targets are on the routine tragic hit list of activities of Southern Hemisphere. This may partly be due to extra large land of Northern Hemisphere than that of Southern giving rise to more and rapid temperature fluctuations and thus 


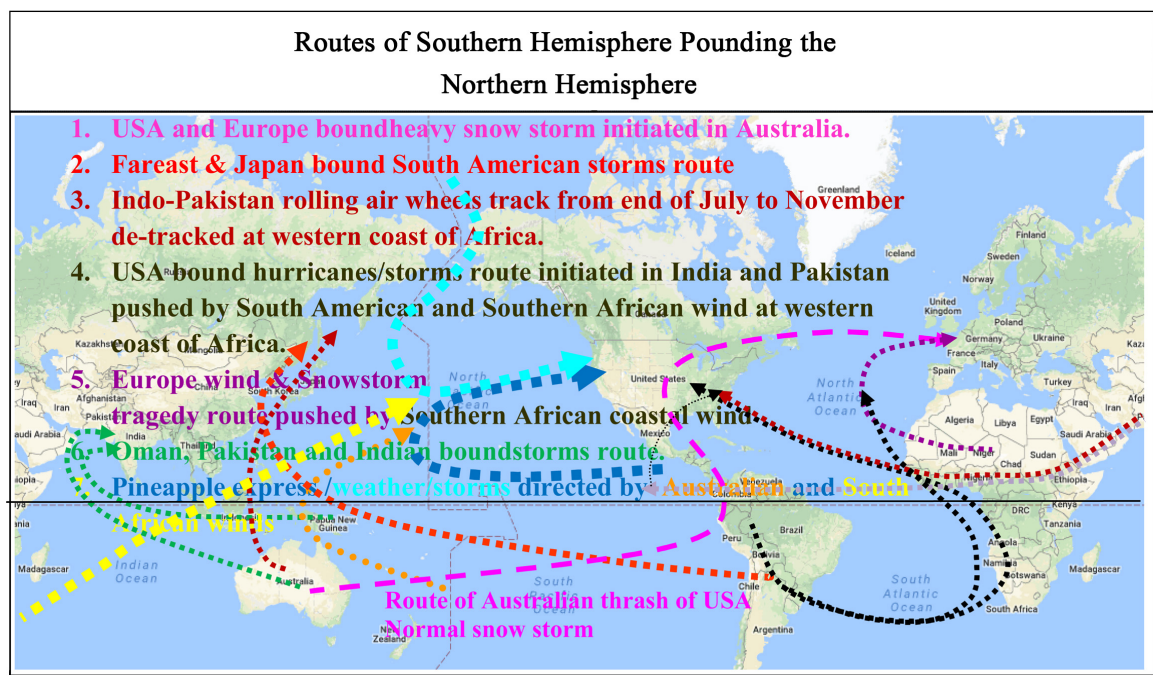

Figure 5. Tracks of southern hemisphere energetic winds lashing on northern hemisphere.

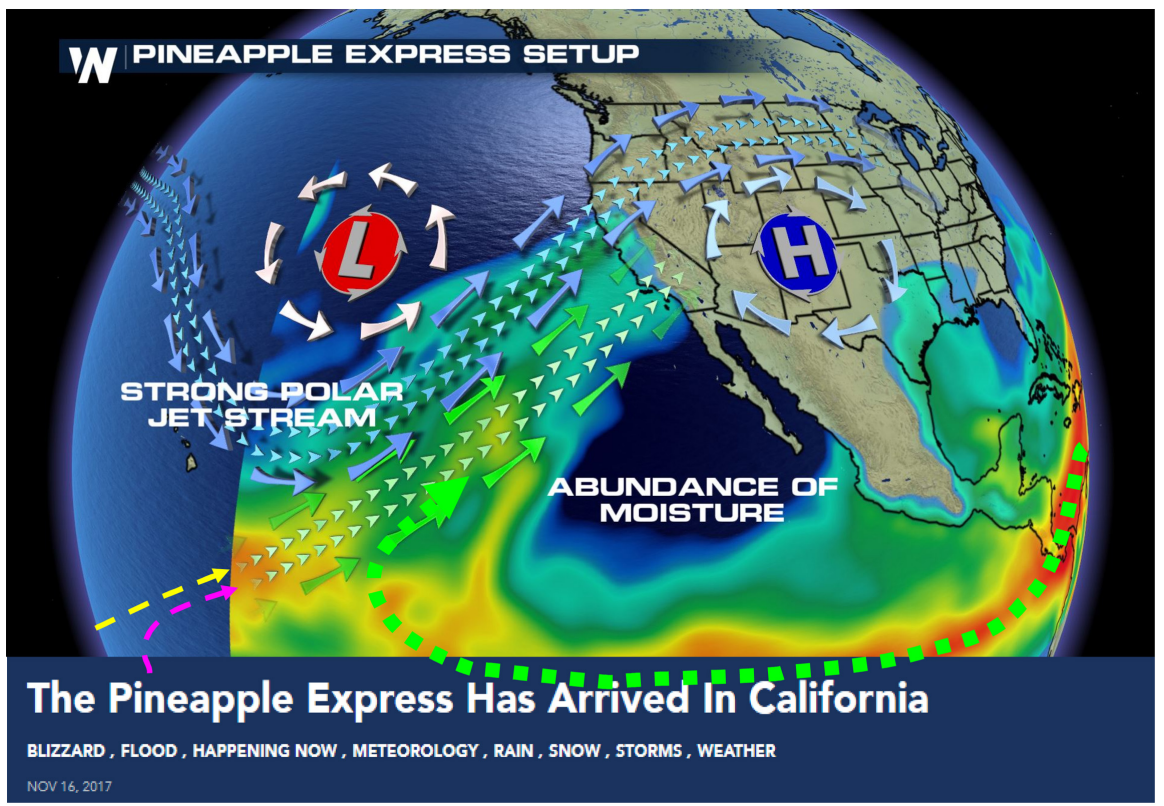

Figure 6. Pineapple express setup shows the route, ultimately around the South West American High Pressure Zone $(\mathrm{H})$ circulation and contributors; 1) strong polar jet stream creating low pressure Zone (L) circulation over Northern East Pacific and 2) high speed and high temperature Easterly or Trade Wind, both converged into 250 - $375 \mathrm{Km}$ wide atmospheric river by 3 ) the Australian and 4) South African gust across the Pacific \& Indian Ocean respectively.

atmospheric pressure and humidity variations than the south and partly due to strong Easterly Wind strengthened by heating behavior of large deserts on this side of Equator while strong westerly on southern side with the help of coastal and mountains structures and the orientation forced the southern wind to crossover the Easterly to the Northern hemisphere, thus the two behaving as westerly-easterly diode. In Warming, Northern Hemisphere is outpacing the South 


\section{How an atmospheric river works}

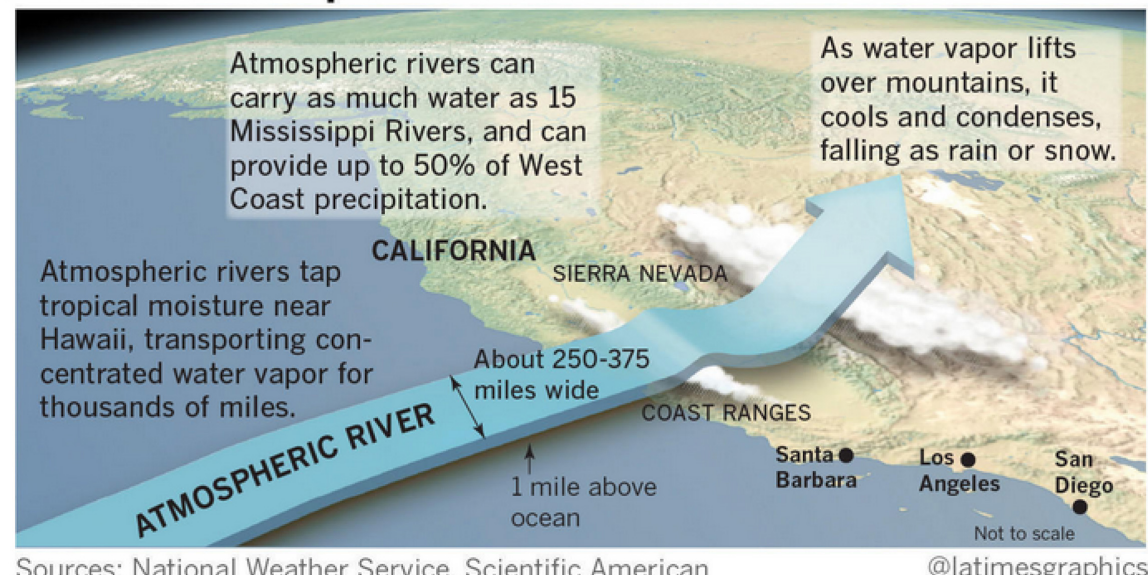

Figure 7. Working of pineapple express atmospheric river.

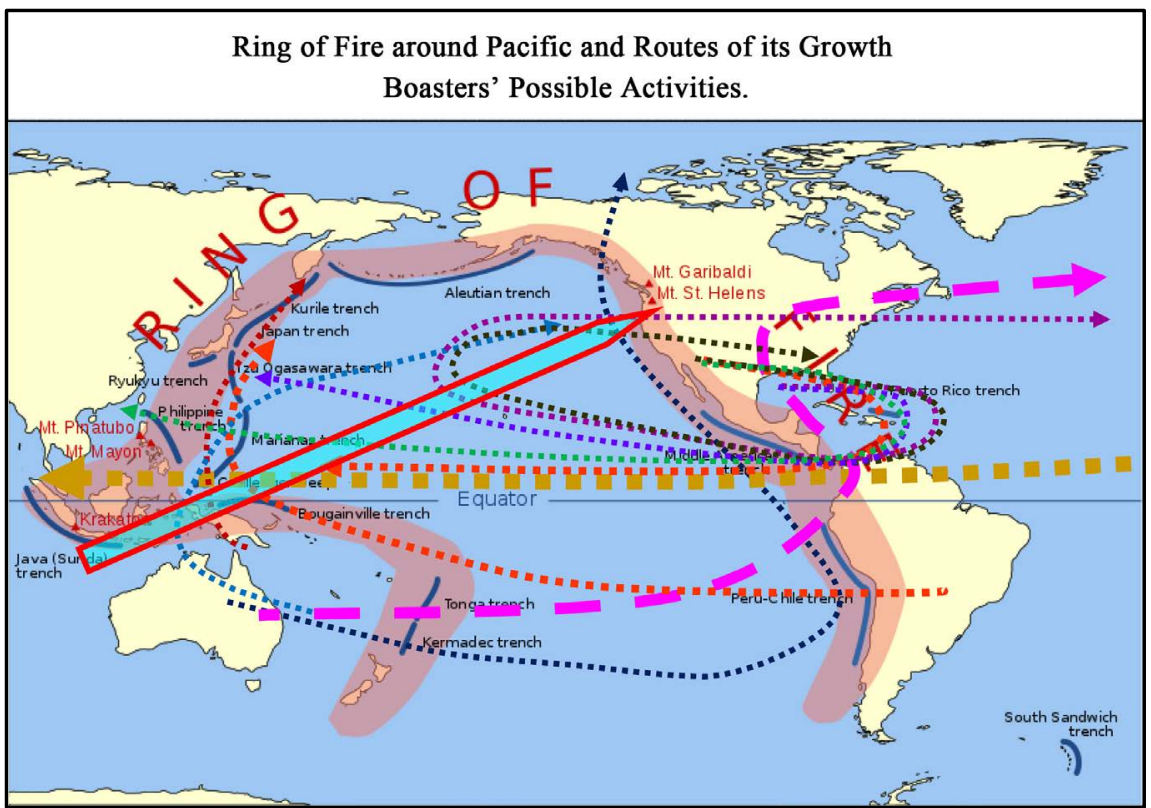

Figure 8. Pacific ring of fire heated by easterlies backed in Indian subcontinent, middle and Africa, Australian desert heated winds and both the North and South America jungle fires as pointed out in Figure 2 and Figure 4 and Pineapple atmospheric river express.

[12] and this may be the contribution of easterly-westerly diode.

It is stated by some experts that earthquakes and volcanic eruption in the Ring of Fire around Pacific Ocean (Figure 8) is becoming more active in 2018. The troikas of Global Temperature, Large Tribe of California Jungle Fires, Hawaiian Volcanic Eruption, Pineapple atmospheric river express, Easterlies and many others (as shown in Figure 6) may have particular role in it as Pacific Ocean has been the main field of all their joint ventures (see Figure 4 also). It seems that the said troika has continuously heated the Northern Pacific and thus reduced the temperature difference between earth surface and its core which abstracted the natural heat flow from the earth core to surface resulting into heat accumu- 
lation in its core which may explode the volcanoes, earthquakes and tsunamis.

\section{Conclusions}

Following may be concluded from the above discussion.

1) The aftermath of California Jungle Fires and Hawaiian Volcanic Eruption has unearthed the extremely critical status of Global Heat contents and Temperature, particularly after 1973 and warned that Extreme Global Warming is the main culprit behind most of the wildfires, global calamities and hazards.

2) Any event of extraordinary heat addition in the Northern Hemisphere of Earth Global results in number of calamities only or at least mainly in the Northern Hemisphere.

3) Any event of extraordinary heat addition in the Southern Hemisphere of Earth Global like Australian, African or Southern American Wildfires or volcanic eruption results in number of calamities mainly in the Northern Hemisphere.

4) Large land area, higher temperature, low pressure and humidity in the northern hemisphere along with diode like behavior of Easterly and southern Westerly assisted by coastal and mountains structures and orientations with respect to earth rotation form a barrier for containment of northern activist event mainly within the north, while an easy passage is provided for the southern to crossover to the north.

5) Global heat content with temperature and wildfire events have strong bilateral support relation. Wildfire events are on rise due to extreme rise in Global Temperature and these fires are pushing the Global heat content and Temperature further up and up.

6) Wildfire, fossil fuel and explosives usage adds huge quantity of heat directly to the global environment and many times more than this indirectly through blockage of heat flow to the Outer Space by their soot, pollution and Green House Gasses generated.

7) Volcanic eruption events, Tsunamis and Magma Based Earthquakes are also on rise and this also seems to be due to extreme rise in Global Temperature as it reduces the normal heat flow from the earth interior core to the surface, as the driving temperature difference is reduced. This results in heat accumulation in the earth core which bursts out in shape of volcanic eruption and this pushes the Global Temperature further up and up along with promoting number of other sever Global hazards.

8) The Northern Pacific Ocean being the major field and passage of all the traffic of all the tragic event generated by California wildfire, Hawaii volcanic eruption along with most of the other Jungle Fires and volcanic eruptions, it may badly agitate the Pacific Ring of Fire resulting into more volcanic eruptions and sever Magma Based Earthquakes and Tsunamis.

9) A huge activist has come into play during 1960-1973, which has extremely boasted the Global heat content and temperature dominating and overruling the 
features of all other activists.

\section{Recommendations}

It is recommended strongly that

1) Control and Blockage of Global Warming and measures for its rolling back to the safe status before 1960 must be given special considerations, concentration and priorities over all the local or Global measure about safe environmental preservation activities. UNO should immediately manage all these activities and arrange finances for this on logical basses; for example, fossil fuel and explosive producers and users may be charged suitably from some previous year say 1948 and also mismanaged Wildfires depending on its size may be charged from responsible country since 2010 .

2) Strict International Wildfires Containment Regulations may be formulated and implemented immediately by UNO and losses and damages caused by these events must be compensated through charges levied on the responsible.

3) Studies through Universities on beneficial use of volcanic energy well prior to its eruption must be sponsored and viable techniques for its transfer may be implemented or at least its slow, controlled and continuous release must be initiated.

4) The critical active sites of both Wildfire and Volcanic Eruption should be marked and countries belonging to these may be warned for their containment.

5) International Courts and UNO offices must be upgraded and discrepancies must be removed for early justice and settlement of International issues, because these lead to wars which contribute much to the addition of heat, soot, pollution and Green House Gasses through use of explosives and all these are extremely dangerous for Global Heat Contents, Temperature and Environments leading to number of extremely sever hazards.

6) Production and use of Fossil Fuel and explosives etc. must be discouraged and internationally taxed heavily to arrange finances for blockage and down tracking activities of Global Heat Contents and temperature rise.

7) Power generation from fossil fuels may be discouraged and taxed heavily for financing their production from hydro, solar, wind, Oceanic tides and currents etc.

\section{Conflicts of Interest}

The author declares no conflicts of interest regarding the publication of this paper.

\section{References}

[1] Nazeer, M.M. (2003) Pakistan Resources Proficiency in Global Fever, Greenhouse Gasses and Atmospheric Pollution Control and Need of Their Mobilization. NSMTCC97 on Environmental Pollution, Islamabad, 24-26 February 1997.

[2] Cheng, L.J., Trenberth, K.E., Fasullo, J., Boyer, T., Abraham, J. and Zhu, J. (2017) Improved Estimates of Ocean Heat Content from 1960 to 2015. Science Advances, 
3, e1601545 http://advances.sciencemag.org/content/3/3/e1601545.full

[3] Wikipedia, List of Wildfire Events, Top Wildfire Events.

https://www.eea.europa.eu/data-and-maps/figures/global-annual-average-temperat ure-deviations-1850-2007-relative-to-the-1850-1899-average-in-oc-the-lines-refer-t o-10-year-moving-average-the-bars-to-the-annual-land-and-ocean-global-average2/observed-global-annual-average-temperature

[4] https://www.eea.europa.eu/data-and-maps/indicators/global-and-european-temper ature/global-and-european-temperature-assessment-4

[5] Nazeer, M.M., et al. (1998) Role of Earth Shape and Rotation in Generating and Tracking of Cyclones. Journal of Natural Science and Mathematics, 38, 217-227.

[6] https://en.wikipedia.org/wiki/Hurricane_Florence

[7] https://www.theguardian.com/world/2018/sep/04/typhoon-jebi-japan-hit-by-strong est-storm-for-25-years

[8] https://en.wikipedia.org/wiki/Hurricane_Michael

[9] https://www.infoplease.com/2018-current-events

[10] http://www.weathernationtv.com/news/pineapple-express-arrived-california/

[11] https://www.latimes.com/la-me-ln-what-is-an-atmospheric-river-pineapple-express -20180321-htmlstory.html

[12] Andrew Freedman (2013) In Warming, Northern Hemisphere is Outpacing the South. Journal of Climate.

http://www.climatecentral.org/news/in-global-warming-northern-hemisphere-is-ou tpacing-the-south-15850 